\title{
Consumo de cánnabis de los adolescentes y esquizofrenia: evidencias epidemiológicas y experimentales
}

\section{Adolescent cannabis consumption and schizophrenia: epidemiological and experimental evidences}

| Daniela Parolaro

\section{RESUMEN}

La marihuana es la droga ilegal más utilizada entre los adolescentes. La mayoría de los usuarios comienzan además a experimentar con ella durante este periodo. La adolescencia es una etapa crítica, que incluye no sólo la maduración reproductiva, sino también la cognitiva, emocional y social de maduración. El cerebro del adolescente está aún en transición, difiriendo tanto anatómica como neuroquimicamente del adulto. El sistema endocannabinoide es un determinante importante para la maduración cerebral, por lo que su importante estimulación a través del delta-9-tetrahidrocannabinol, que actúa a través del sistema endocannabinoide, podría conducir a cambios neurobiológicos sutiles pero duraderos, que pueden afectar las funciones cerebrales y el comportamiento incluso cuando ya es adulto. Resumimos las más recientes investigaciones acerca de la exposición de los adolescentes a los cannabinoides y el riesgo de trastornos psicóticos como la esquizofrenia, como se desprende de los estudios tanto humanos como animales. La evidencia epidemiológica sugiere que el consumo de cannabis es un factor de riesgo para la esquizofrenia, y contibuye a la exacerbación de los sintomas y al empeoramiento del pronóstico en individuos con predisposición. Las características del cerebro adolescente, probablemente lo hace más vulnerable a los efectos del cannabis produciendo sintomas similares a los psicóticos y posiblemente causando la esquizofrenia.

Palabras claves: cannabis, adolescencia, psicosis, esquizofrenia, cerebro.
Enviar correspondencia a:

Daniela Parolaro

DBSF and Center of Neuroscience. University of Insubria.

Via A. da Giussano 10, 21052 Busto Arsizio (Narese), Italy.

E-mail: daniela.parolaro@uninsubria.it

\section{ABSTRACT}

Marijuana is consistently the most widely used illicit drug among teenagers and most users first experiment it in adolescence. Adolescence is a critical period between childhood and adulthood, including not only reproductive maturation, but also cognitive, emotional and social maturation. In this period adolescent brain is still in transition differing anatomically and neurochemically from the adult's one. The endocannabinoid system is an important determinant for cerebral maturation, therefore its strong stimulation by the delta-9tetrahydrocannabinol, that acts through the endocannabinoid system, might lead to subtle but lasting neurobiological changes that can affect adult brain functions and behaviour. We summarize the more recent researches investigating the relationships between adolescent exposure to cannabinoids and increased risk for psychotic disease such as schizophrenia, as highlighted by both human and animal studies. Epidemiological evidence suggests that cannabis use is a risk factor for schizophrenia, and an exacerbation of symptoms and worsening of the schizophrenic prognosis may occur in individuals with a predisposition for schizophrenia. The characteristic of adolescent brain probably makes it more vulnerable to cannabis effect producing psychotic like symptoms and possibly cause schizophrenia.

Key words: Cannabis, adolescence, psychosis, schizophrenia, brain 


\section{The endocannbinoid system}

$\mathrm{T}$ he endocannabinoid system is a recently discovered signalling system located in both brain and periphery'. It comprises the G-protein coupled cannabinoid CB1 and CB2 receptors, their endogenous lipid ligands, the endocannabinoids (ECs), and associated proteins (transporters, biosynthetic and degradative enzymes). The cannabinoid CB1 receptor is a presynaptic receptor widely expressed throughout the brain and present at lower density in peripheral tissues, whereas CB2 receptor is predominately located in immune cells and in tissues such as the spleen and liver, although there is evidence for the presence of cannabinoid CB2 receptors in the brain'.

The two primary endogenous ligands which have been characterized as endocannabinoids are the $\mathrm{N}$-arachidonoylethanolamine, or anandamide (AEA), and 2-arachidonoylglycerol (2-AG). Both AEA and 2-AG are synthesized post-synaptically from phospholipid precursors through activity-dependent activation of specific phospholipase enzymes. AEA is hydrolyzed by the enzyme fatty acid amide hydrolase (FAAH), generating arachidonic acid and ethanolamine, while 2-AG is primarily metabolized by monoacylglycerol lipase (MAG lipase), which results in the formation of arachidonic acid and glycerol.

The endocannabinoid signalling acts differently from most neurotransmitter systems and endocannabinoids are released "on demand" by post-synaptic cells, acting as retrograde messengers and traverse back across the synapse where they bind to pre-synaptically located $\mathrm{CB} 1$ receptors reducing synaptic transmitter release.

Endocannabinoid signalling has been found to be present during the gestational period and several studies have been focused on the relevance of this system for neural developmental processes. During early phases of neuronal development, endocannabinoid signalling is fundamental for the proliferation and differentiation of progenitor cells, axonal guidance, neuronal migration, fasciculation, positioning of cortical interneurons, neurite outgrowth and morphogenesis ${ }^{2,3}$. A series of important aberration have been described to occur following disruption of normal endocannabinoid signalling during ontogenetic phases.

Adolescence refers to the developmental time period between childhood and adulthood, and in humans is generally considered to encompass the ages of 12 to 17 . Brain maturation continues into adolescence and the precise role of endocannabinoid signalling during the adolescence has not been experimentally elucidated yet but is reasonable that the neurodevelopmental and morphogenic roles of endocannabinoids persist in adolescence. This hypothesis is reinforced by the dynamic changes that occur in the ontogenetic development of the endocannabinoid system during adolescence. In this view a strong stimulation of the endocannabinoid system through cannabis consumption during adolescence may disrupt the normal endocannabinoid signalling producing long-standing consequences on adult brain function.

\section{Schizophrenia: human studies}

A number of studies have investigated whether exposure to cannabis during adolescence may represent a risk factor for developing psychotic disorders such as schizophrenia ${ }^{4,5}$. A longitudinal study, performed in Dunedin (New Zealand), highlighted that cannabis users by age 15 and 18 had more schizophrenic symptoms compared to controls (never smoked cannabis or had used cannabis "once or twice") at age 26. Moreover, earlier use at age 15 conferred a greater risk of schizophrenia outcomes than later use. In contrast, a systematic review of longitudinal studies published in 2004 failed to demonstrate a causal relationship between cannabis in adolescence and psychosocial harm, but could not exclude the possibility that such a relation exists ${ }^{6}$.

More recently, in Zurich (Switzerland), an increase in first admission rates of patients with schizophrenia and other psychotic disorder was observed in the second half of the 1990s in males aged between 15 and 197. Concomitantly, there was an increase in the use of cannabis among 15 to 16 year old Swiss boys from 15\% in 1990 to $41 \%$ in 1998, suggesting that this may be the reason for the higher admission rates. In another study performed in Greece and enrolling 3.500 19-years teenagers, the use of cannabis in adolescence was positively associated with both the positive and negative symptoms of schizophrenia, strongly highlighting that cannabis represents a risk factor for the development of schizophrenia when used in adolescence ${ }^{8}$. Accordingly, adolescent of 15 to 16 year old who had smoked cannabis presented more likely or more symptoms of psychosis when compared to non smokers. Finally, two studies have found increased schizotypy among american undergraduate college students (mean age 21.7 years) and English University students (mean age 22 years) who used cannabis s, $^{10}$.

Sugranyes et al11 recently confirmed that cannabis use was significantly associated with a decrease in age of onset of schizophrenia and this is of particular relevance considering that it has been proved that the early onset of schizophrenia is a negative outcome factor. A study in Spain enrolling patients with first episode psychosis (average age 15.5 years) showed a higher rate of positive symptoms and less negative symptoms and these episodes were more frequently observed in cannabis smokers compared with non smokers.

Summarizing, several studies suggest the presence of a causal link between adolescent cannabis use and the development of psychosis such as schizophrenia. The discrepancies between epidemiological studies can be ascribed to variability in the evaluation of psychotic symptoms and in the control of confounding factors.

There is urgent need for multidisciplinary research approaches, to build a scientific-based opinion on the longlasting consequences of cannabis use in adolescence, and the results might impact the quality of basic knowledge and its translation at human level. 


\section{Animal studies}

Despite the increasing use of cannabis among adolescents, experimental studies focused on long-lasting effects of adolescent cannabinoid exposure on psychosisrelated behaviours in adult rodents are very scarce ${ }^{12}$. The experimental models currently available suffer several limitations and often represent only certain aspects of the pathology, making it difficult to translate the findings to the human condition.

Several papers are focused on the effect of adolescence exposure on cognitive performance. Adolescent exposure to synthetic or natural cannabinoid agonists has been reported to induce impairments in object recognition memory at adulthood in both male and female rats and in spatial working memory without affect other forms of memory (aversive memory or spatial learning) ${ }^{13,14}$. Moreover adolescent exposure to THC worsened the cognitive impairment induced by intermittent chronic administration of phencyclidine, an animal model of schizophrenia-like cognitive deficit ${ }^{15}$. In contrast the co-treatment with the CB1 receptor antagonist $\mathrm{AM} 251$ recovered $\mathrm{it}^{16}$.

Only few papers dealt with the relationship between adolescent cannabis use and vulnerability to other schizophrenia-like symptoms in adulthood. Schneider and Koch $^{13,14}$ using male rats treated with synthetic WIN5521-2, observed a deficit in the prepulse inhibition of the startle reflex (PPI), when tested in adulthood. Chronic treatment with THC or the synthetic cannabinoid CP-55,940 during adolescence induced a significant decrease in social behaviour measured in the social interaction test ${ }^{17}$. Adult rats exposed to WIN 55,212-2 during adolescence showed a significant increase in locomotor activity when tested in the open field. Furthermore, THC worsens disruption of PPI induced by isolation rearing, but has no effect on PPI in rats that are not socially isolated ${ }^{18}$.

The molecular and cellular mechanisms by which adolescent exposure to cannabinoids favour the probability to develop schizophrenia-like symptoms are still unclear. Interestingly, when an animal model used to induce schizophrenia-like symptoms was used during the periadolescent period, a decrease in CB1 receptor expression and/or $\mathrm{G}$ protein coupling has been observed in cerebral areas relevant to schizophrenia. Reciprocal increase in FAAH and decrease $\mathrm{CB} 1$ receptor expression was present in the caudate putamen of socially isolated rats ${ }^{19}$, an environmental model of schizophrenia and a specific increase in 2-AG levels was measured in the PFC of rats chronically treated with phencyclidine (PCP), associated with reduced functionality of the CB1 receptor in this brain area ${ }^{15}$. In line with this, in the hippocampus of maternally deprived rats a decrease in $\mathrm{CB} 1$ receptor expression and an increase in 2-AG levels have been observed.

Moreover, adolescent THC exposure in male rats provoked lasting changes in the hippocampal protein expression profiles related to degenerative and oxidative changes as well as impairment in plasticity of both neurons and glia in this brain region, accompanied by a reduction in dendrite length and complexity and number of dendritic spines in the dentate gyrus ${ }^{20}$. In female rats, adolescent THC exposure induced in the PFC a reduction in synaptic density and/or efficiency ${ }^{21}$. Therefore, adolescent cannabinoid exposure triggers a plethora of cellular and molecular events in the brain that could be involved in the development of the different symptoms of schizophrenia.

Recently also an increase in CB2 receptor expression in hippocampal regions of maternal deprived rats was observed $^{22}$. The authors suggested a role for CB2 receptors in the psychotic like behavioral alterations observed in this animal model. Moreover, Ishiguro and colleagues ${ }^{23}$ described a polymorphism in the gene encoding for CB2 receptors associated with schizophrenia in a Japanese population. Additionally, administration of the CB2 receptor antagonist worsened disruption of PPI induced by the NMDA receptor antagonist MK-801 in rats. Thus, CB2 receptors could be another actor involved in psychotic like symptoms associated with cannabis consumption.

\section{Possible mechanism}

The mechanism by which adolescent cannabis consumption could increase the susceptibility to psychoses such as schizophrenia is still unclear. Recent studies have found that endocannabinoid system is implicated in schizophrenia and post mortem alteration in CB1 receptor have been observed in brain of schizophrenic patients in some studies. Taken together, these observations indicate a dysregulation of the endocannabinoid system in schizophrenia and suggest an "endocannabinoid hypothesis of schizophrenia".

Furthermore, it has been suggested that the endocannabinoid system may act as a protective mechanism whereby endocannabinoids are released in response to an hyperdopaminergic state in an attempt to decrease dopaminergic transmission ${ }^{24,25}$. Thus, it is possible that repeated use of cannabis in adolescence leads to sensitization of the endogenous mesolimbic dopaminergic system and this is why cannabis use during adolescence results in a worse outcome with respect to development of schizophrenia compared with ingesting cannabis during adulthood.

In the last 5 years a number of studies has highlighted that an increased risk of developing adult psychosis exists in patients with the COMT Valine polymorphism following adolescent cannabis exposure. These authors suggested that the observed gene $x$ environment interaction may be limited to a sensitive period of brain development in adolescence ${ }^{26}$. However, this was not replicated in a cohort of approximately 500 UK patients with schizophrenia.

Finally, it may be remembered that the frequency and amount of cannabis consumed in addition to the different forms of preparation are variable factors that are difficult to take into account. Moreover, the amount of the major psychoactive constituent THC varies in the different cannabis varieties ranging from the classical $2 \%$ to $20 \%$ in some preparation. In addition, the concentration of other 
cannabinoids in cannabis preparations may be important in determining the susceptibility to schizophrenia following cannabis use. In fact, animal studies as well as clinical studies show that the non psychoactive constituent cannabidiol has antipsychotic activity ${ }^{27,28}$. In addition, it has been suggested that cannabidiol may protect against some Pro-psychotic effects of $\mathrm{THC}^{27}$.

\section{CONCLUSION}

The neurodevelopmental characteristic of adolescence probably creates a more vulnerable circumstance for cannabis to produce psychotic-like symptoms and possibly cause schizophrenia. Epidemiological data suggest that cannabis abuse is a risk factor for the onset of schizophrenia and, in individuals with a predisposition for schizophrenia, the ingestion of cannabis exacerbates symptoms and worsens the schizophrenic prognosis. Due to the important role of the endocannabinoid system in moderating adolescent neurodevelopmental processes, we can speculate that adolescent exposure to cannabinoids might alter the normal developmental neuronal processes involved in brain maturation, thus leading to a predisposition to develop schizophrenia, possibly inducing dysfunction in the more relevant neurotransmitter systems such as GABAergic and dopaminergic transmission. Moreover, some adolescents possess a genetic vulnerability in the COMT gene that makes them more susceptible to the pro-psychotic effects of cannabis. To further investigate the role of the endocannabinoid system in neurodevelopment, as well as molecular and neurochemical consequences of adolescent cannabinoid exposure, preclinical studies are needed to enhance our knowledge on the link between adolescent use of cannabis and schizophrenia.

\section{REFERENCES}

1. Piomelli D. The molecular logic of endocannabinoid signalling Nat Rev Neurosci 2003; 4: 873-84.

2. Harkany T, Mackie K. \& Doherty P. Wiring and firing neuronal networks: endocannabinoids take center stage. Curr Opin Neurobiol 2008; 18: 338-45.

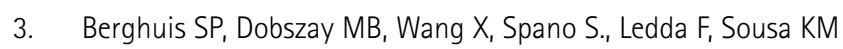
et al. Endocannabinoids regulate interneuron migration and morphogenesis by transactivating the TrkB receptor. Proc Natl Acad Sci U S A 2005; 102: 19115-20.

4. D'Souza DC, Sewell RA, Ranganathan M. Cannabis and psychosis/schizophrenia: human studies. Eur Arch Psychiatry. Clin Neurosci 2009; 259: 413-31.

5. Sewell RA, Ranganathan M, D'Souza, DC. Cannabinoids and psychosis. Int Rev Psychiatry 2009; 21: 152-62.

6. Macleod J, Oakes R, Copello A, Crome I, Egger M, Hickman M et al. Psychological and social sequelae of cannabis and other illicit drug use by young people: a systematic review of longitudinal, general population studies. Lancet 2004; 363:1579-88.

7. Ajdacic-Gross V, Lauber C, Warnke I, Haker H, Murray RM, Rossler W, Changing incidence of psychotic disorders among the young in Zurich. Schizophr Res 2007, 95:9-18.

8. Stefanis NC, Delespaul P, Henquet C, Bakoula C, Van Os J. Early adolescent cannabis exposure and positive and negative dimensions of psychosis. Addiction 2004; 99: 1333-41.

9. Schifman J, Nakamura B, Earleywine $M_{1}$ Labrie J Symptoms of schizotypy precede cannabis use. Psychiatry Res 2005; 134:37-42.

10. Barkus E., Lewis S. Schizotypy and psychosis-like experiences from recreational cannabis in a non-clinical sample. Psychol Med 2008; 38:1267-76.

11. Sugranyes G, Flamarique I, Parellada E, Baeza I, Goti J, Fernández-Egea E, Bernardo M. Cannabis use and age of diagnosis of schizophrenia. Eur Psychiatry 2009; 24: 282-6.

12. Realini N, Rubino T. Parolaro D. Neurobiological alterations at adult age triggered by adolescent exposure to cannabinoids. Pharmacological Research 2009; 60: 132-8.

13. Schneider $M$, Koch $M$. Chronic pubertal, but not adult chronic cannabinoid treatment impairs sensorimotor gating, recognition memory, and the performance in a progressive ratio task in adult rats. Neuropsychopharmacology 2003; 28: 1760-69.

14. Schneider, M, Koch $M$. The effect of chronic peripubertal cannabinoid treatment on deficient object recognition memory in rats after neonatal mPFC lesion. Eur Neuropsychopharmacol 2007; 17: 180-6.

15. Vigano D, Guidali C, Petrosino $S$, Realini N, Rubino T, Di Marzo V, Parolaro D. Involvement of the endocannabinoid system in phencyclidine-induced cognitive deficits modelling schizophrenia. Int J Neuropsychopharmacol 2009; 12: 599-614.

16. Guidali $C$, Viganò $D$, Petrosino $S$, Zamberletti $E$, Realini $N$, Binelli et al. Cannabinoid CB1 receptor antagonism prevents neurochemical and behavioural deficits induced by chronic phencyclidine. Int J Neuropsychopharmacol 2010 Mar 3:1-12. [Epub ahead of print].

17. Malone DT, Jongenan D, Taylor DA. The effect of cannabidiol on open field behaviours induced by 9-tetrahydrocannabinol in rats. Pharmacol Biochem Behav 2009; 93: 91-6.

18. Malone DT, Taylor DA. The effect of Delta9-tetrahydrocannabinol on sensorimotor gating in socially isolated rats. Behav Brain Res 2006; 166:101-9.

19. Sciolino NR, Bortolato $M$, Eisenstein SA, Fu J, Oveisi $F$, Hohmann $A G$ et al. Social isolation and chronic handling alter endocannabinoid signaling and behavioral reactivity to context in adult rats. Neuroscience 2010; 168: 371-86.

20. Rubino T, Realini, N, Braida D, Guidi S, Capurro V, Vigano D et al.. Changes in hippocampal morphology and neuroplasticity induced by adolescent THC treatment are associated with cognitive impairment in adulthood. Hippocampus 2009; 8: 763-72.

21. Rubino T, Realini, N, Braida D Alberio T, Capurro V, Vigano D et al. The depressive phenotype induced in adult female rats by adolescent exposure to THC is associated with cognitive impairment and altered neuroplasticity in the prefrontal cortex. Neurotox Res 2009; 15: 291-302.

22. Suarez J, Llorente R, Romero-Zerbo SY, Mateos B, BermudezSilva F, De Fonseca F.R. et al Early maternal deprivation induces gender-dependent changes on the expression of hippocampal 
$\mathrm{CB}(1)$ and $\mathrm{CB}(2)$ cannabinoid receptors of neonatal rats. Hippocampus 2009; 19: 623-32.

23. Ishiguro $H_{1}$ Horiuchi $Y$, Ishikawa $M$, Koga $M$, Imai $K$, Suzuki $Y$, et al Brain Cannabinoid CB2 Receptor in Schizophrenia. Biol Psychiatry 2010; 67: 974-82.

24. Leweke FM, Giuffrida A, Wurster U, Emrich HM, Piomelli D. Elevated endogenous cannabinoids in schizophrenia. Neuro Report 1999; 10: 1665-9.

25. Leweke FM, Koethe D. Cannabis and psychiatric disorders: it is not only addiction. Addict Biol 2008; 13: 264-75.

26. Caspi A, Moffitt TE, Cannon M, Macclay J, Murray R, Harrington $\mathrm{H}$ et al. Moderation of the Effect of Adolescent-Onset Cannabis
Use on Adult Psychosis by a Functional Polymorphism in the Catechol-0-Methyltransferase Gene: Longitudinal Evidence of a Gene X Environment Interaction. Biological Psychiatry 2005; 57 : 1117-27.

27. Malone DT, Jongegan D, Taylor DA. The effect of cannabidiol on open field behaviours induced by 9-tetrahydrocannabinol in rats. Pharmacol Biochem Behav 2009; 93: 91-96.

28. Leweke FM, Schneider U, Radwan M, Schmidt E, Emrich HM. Different effects of nabilone and cannabidiol on binocular depth inversion in Man. Pharmacol Biochem Behav 2000; 66: 175-81. 
